\title{
Prevalence and Risk Factors of Episiotomy and Perineal Tear in the Maternity Teaching Hospital of Erbil City, Iraq
}

\author{
Hamdia Mirkhan Ahmed; Department of Midwifery, College of Nursing, Hawler Medical University, Erbil, Iraq. \\ Warda Hasan Abdollah; Department of Midwifery, College of Nursing, Hawler Medical University, Erbil, Iraq. \\ (Correspondence: hamdia.mirkhan@nur.hmu.edu.krd)
}

Namir Ghanim Al-Tawil; Department of Community Medicine, College of Medicine, Hawler Medical University, Erbil, Iraq.

\section{ABSTRACT}

Background and Objectives: During childbirth, women are at risk for experiencing perineal trauma to the genitalia resulting in a tear of the perineum or the surgical process of an episiotomy. Knowing the prevalence and the risk factors associated with perineal trauma may help in the reduction of episiotomy and prevention of occurrence of tear. The aim of the study was to find out the prevalence and risk factors associated with perineal trauma among women ages 15-48.

Methods: A cross sectional study was conducted in the Maternity Teaching Hospital of Erbil, Kurdistan region, Iraq. All records of mothers $(n=1500)$ who had been admitted to the delivery room for vaginal delivery during the month of May (2015) were reviewed. Chisquare test of association and binary logistic regression were used to interpret the data.

Results: The overall rates of episiotomy, tear, their combined presence, and an intact perineum were: $47.8 \%, 7.2 \%, 26.1 \%$ and $18.9 \%$, respectively. Incidence of having an episiotomy, tear, or combination of both, were significantly associated with women of young ages and women who were primigravida parity. There was a statistically significant association between high birth weight and the occurrence of perineal trauma. There was no association between perineal trauma and residency (urban/rural), occupation, gender of baby and time of delivery. Binary logistic regression analysis showed that having an episiotomy increased the risk of a tear by more than $30 \%$.

Conclusions: The prevalence of episiotomy was found to be $73.9 \%$ which is much higher compared to the World Health Organization recommendation which is $10 \%$. Perineal trauma were associated with factors such as age, parity, and birth weight. Episiotomy is a risk factor for a vaginal tear. We recommend further research to inform the development and implementation of restrictive episiotomy policies to reduce and prevent occurrences of perineal trauma.

Key words: perineal trauma, episiotomy, tear, prevalence, risk factors

Received: $28 / 9 / 2018$

Accepted: 25/2/2019

Published: 30/5/2019

\section{INTRODUCTION}

During child birth, tearing to the perineum can occur naturally or by the surgical process of an incision known as episiotomy. Both natural tearing and episiotomy are found to be traumatic to the genitalia [1]. Reported rates of episiotomies vary from as low as $9.7 \%$ in Sweden to as high as
$100 \%$ in Taiwan considering both nulliparous and multiparous women [2,3]. More than $85 \%$ of women having a vaginal birth experience some form of perineal trauma, and $60-70 \%$ of women receive sutures post-delivery to repair the perineum. Approximately one-third of the women in the United States and the United Kingdom 
experience spontaneous tears to the perineum during delivery [2].

Women are affected by perineal trauma in the intermediate postnatal period and can extend beyond this period. The impact of perineal trauma to women's physical, psychological, and social wellbeing may lead to negative effects on family life, disruption of breastfeeding, and sexual relations. A study done in the UK showed that a considerable proportion of women continue to experience short-term complications such as pain, discomfort, dyspareunia, fecal incontinence, and urinary problems during the postpartum period. Depending on the severity of perineal trauma, some women may experience continued pain as a longterm effect due an expected complication. In addition, whether of not trauma management was effective plays a role in the continued experience of long-term pain. [3].

A 2009 systematic review of eight randomized trials found that women who gave birth in sites with restricted episiotomy policies experienced less severe perineal trauma, less requirement for suturing, and fewer complications, compared to women who gave birth in sites with routine episiotomy policies. In addition, women who gave birth in sites with restricted episiotomy policies presented no difference in pain, urinary incontinence or dyspareunia, however they had a higher risk of anterior perineal damage [4].

According to two previous studies conducted in Kurdistan, most of the midwives reported that the rate of episiotomy was high in their hospitals. They attributed this to the common practices of midwives and obstetricians and policies of the hospitals in their health system [5].

Another study showed that most of the reasons given by the midwives for performing episiotomies were not evidence-based [6]. No study was done for determining the rate of episiotomy and perineal tear in Kurdistan's maternity hospitals. The authors believe that knowing the prevalence and risk factors of perineal trauma during delivery may lead to a decrease in the incidence of vaginal tear. The aims of this study are to determine the prevalence and risk factors associated with perineal trauma in the Maternity Teaching Hospital in Erbil city. Owing to the lack of research in this field in Erbil city, the results of this study will provide valuable information leading to better practices in the delivery room. In addition, the results of this study may be used to inform and develop new evidence-based guidelines to help decrease the rate of episiotomies and prevent the occurrence of vaginal tears during childbirth.

\section{METHODS}

A retrospective cross-sectional study was conducted in the postpartum unit of the Maternity Teaching Hospital located in Erbil city in the Kurdistan region of Iraq. This hospital is a public site hosting 300 patient beds. Records of mothers who had been admitted to the delivery room for vaginal delivery $(n=1500)$ during the month of May (2015) were reviewed.

As per hospital policy, the decision for performing episiotomy are made by midwives during the second stage of delivery. It is important to note the difference in educational (graduated from a school, institute or college of nursing/midwifery) and experience levels among midwives within the hospital. A tool was developed for the purpose of data collection and included demographic and obstetrical characteristics of mothers who had an episiotomy, vaginal tear or both. Prior to data collection, permission to conduct the study was obtained from the Scientific and Ethics Committee of College of Nursing/Hawler Medical University and the Erbil General Directorate of 
Health. Data were analyzed using the statistical package for Social Sciences (SPSS, version 22). Chi-square test of association was used to compare proportions.

Fisher's exact test was used when more than $20 \%$ of the cells of the table have expected count less than 5 .

Binary logistic regression was used where the dependent variable was the tear, and the independent variables (included in the regression model) were the factors found to be significantly associated (according to Chi square test) with the development of tear. A $p$ value of $\leq 0.05$ was considered as statistically significant.

\section{RESULTS}

The files of 1500 women admitted to the Maternity Teaching Hospital for a vaginal delivery in May 2015 were reviewed. The mean age + SD of the women was $25.89+$ 6.19 years, ranging from 15 to 48 years. The median was 25 years. The mean + SD of parity was $2.5+1.62$. The mean baby weight was $3580.9+520$ grams, ranging from 1800 to 6000 grams. The median was 3500 grams. Of the 1500 women, more than two-thirds of the women (1109) experienced an episiotomy during childbirth.

Nearly half $(47.8 \%)$ of the women who experienced an episiotomy during childbirth did not develop a vaginal tear and only 391 (26.1\%) women who had episiotomy also experienced vaginal.

The results also show that 108 (7.2\%) women developed vaginal with knowledge of no episiotomy done and there were 283 (18.9\%) women who experienced no episiotomy or vaginal tearing (Table 1 ).

There was a significant association between age and perineum status.

Women less than 20 years of age who had an episiotomy done (57.2\%) did not develop vaginal tearing.

Approximately one-third of the women
(29.4\%) of the same age experienced vaginal tearing in spite of doing an episiotomy. This percentage is much higher compared to women ages 40-49, who experienced both an episiotomy and vaginal tearing ( $p$ $<0.001$ ). A considerable proportion of primiparous women (28.9\%) who experienced an episiotomy also developed a vaginal tear, compared to $17.8 \%$ of the grandmultiparous women $(p<0.001)$.

Among the women who delivered a big baby, approximately one-third (32.4\%) of women experienced tearing in spite of episiotomy compared to $22.7 \%$ of the women women who delivered a small baby developed tearing in spite of episiotomy $(p=$ 0.013 ). There were no significant associations between post-delivery perineum status and residency $(p=0.402)$, occupation $(p=0.223)$, time of delivery $(p=0.493)$, and gender of baby $(p=0.663)$.

Table 2 shows that among all the women, the incidence of a vaginal tear was 33.3\% regardless of whether or not an episiotomy was done. Among these women who experienced an episiotomy, the incidence of a tear was significantly high (35.3\%), compared to the women (27.6\%) without episiotomy ( $p=0.006)$.

Binary logistic regression analysis showed that an episiotomy may increase the risk of a tear by more than 30\% (OR $=1.37 ; 95 \%$ $\mathrm{Cl} 1.045$ to 1.798$)$.No significant association was found between the development of a tear with age, parity, and baby weight (Table 3).

\section{DISCUSSION}

This study reviewed and analyzed the records of 1500 women who experienced a vaginal delivery during a month period. According to WHO, The prevalence rate of episiotomy vary widely from country to country[1]. Compared to the WHO $[7,8]$ recommended rate of episiotomy $(10 \%)$, 
Table 1: Risk factors of episiotomy and tears among study sample

\begin{tabular}{|c|c|c|c|c|c|c|c|c|c|c|}
\hline \multirow[t]{2}{*}{ Variables } & \multirow[b]{2}{*}{$\mathbf{N}$} & \multicolumn{2}{|c|}{$\begin{array}{l}\text { Episiotomy } \\
\text { (No tear) }\end{array}$} & \multicolumn{2}{|c|}{$\begin{array}{c}\text { Tear } \\
\text { (No episioto- } \\
\text { my) }\end{array}$} & \multicolumn{2}{|c|}{ Both } & \multicolumn{2}{|c|}{ None } & \multirow[t]{2}{*}{$p$-value } \\
\hline & & No. & $\%$ & No. & $\%$ & No. & $\%$ & No. & $\%$ & \\
\hline \multicolumn{11}{|l|}{ Age group } \\
\hline$<20$ & 201 & 115 & (57.2) & 7 & (3.5) & 59 & (29.4) & 20 & (10.0) & $<0.001$ \\
\hline $20-29$ & 867 & 421 & (48.6) & 66 & (7.6) & 243 & (28) & 137 & (15.8) & \\
\hline $30-39$ & 374 & 159 & (42.5) & 30 & (8) & 82 & (21.9) & 103 & (27.5) & \\
\hline $40-49$ & 58 & 23 & (39.7) & 5 & $(8.6)$ & 7 & (12.1) & 23 & (39.7) & \\
\hline \multicolumn{11}{|l|}{ Residency } \\
\hline Urban & 672 & 330 & (49.1) & 43 & (6.4) & 181 & (26.9) & 118 & (17.6) & 0.402 \\
\hline $\begin{array}{l}\text { Rural } \\
\text { occupation }\end{array}$ & 828 & 388 & (46.9) & 65 & (7.9) & 210 & (25.4) & 165 & (19.9) & \\
\hline Housewife & 1398 & 665 & (47.6) & 103 & (7.4) & 358 & $(25.6)$ & 272 & (19.5) & 0.223 \\
\hline Employed & 79 & 41 & (51.9) & 5 & (6.3) & 24 & (304) & 9 & (11.4) & \\
\hline Student & 23 & 12 & (52.2) & 0 & (0) & 9 & (39.1) & 2 & (8.7) & \\
\hline \multicolumn{11}{|l|}{ Parity } \\
\hline Primipara & 484 & 311 & (64.3) & 15 & (3.1) & 140 & (28.9) & 18 & (3.7) & $<0.001$ \\
\hline Multipara & 847 & 367 & $(43.3)$ & 83 & $(9.8)$ & 221 & (26.1) & 176 & (20.8) & \\
\hline Grandmulti & 169 & 40 & $(23.7)$ & 10 & (5.9) & 30 & $(17.8)$ & 89 & (52.7) & \\
\hline \multicolumn{11}{|c|}{ Time of delivery } \\
\hline Morning & 374 & 187 & (50) & 31 & (8.3) & 84 & $(22.5)$ & 72 & (19.3) & 0.493 \\
\hline Evening & 394 & 191 & $(48.5)$ & 27 & (6.9) & 110 & (27.9) & 66 & $(16.8)$ & \\
\hline Night & 732 & 340 & $(46.4)$ & 50 & $(6.8)$ & 197 & (26.9) & 145 & (19.8) & \\
\hline \multicolumn{11}{|l|}{ Birth weight } \\
\hline $\begin{array}{l}\text { Low birth } \\
\text { weight }\end{array}$ & 22 & 9 & (40.9) & 1 & (4.5) & 5 & $(22.7)$ & 7 & (31.8) & 0.013 \\
\hline Normal & 1077 & 540 & $(50.1)$ & 83 & $(7.7)$ & 256 & $(23.8)$ & 198 & $(18.4)$ & \\
\hline Big baby & 401 & 169 & $(42.1)$ & 24 & (6) & 130 & (32.4) & 78 & (19.5) & \\
\hline \multicolumn{11}{|l|}{ Sex of baby } \\
\hline Male & 786 & 387 & $(49.2)$ & 53 & (6.7) & 202 & $(25.7)$ & 144 & (18.3) & \\
\hline Female & 707 & 329 & $(46.5)$ & 54 & $(7.6)$ & 186 & (26.3) & 138 & (19.5) & $0.663^{*}$ \\
\hline Twin & 7 & 2 & $(28.6)$ & 1 & (14.3) & 3 & (42.9) & 1 & (14.3) & \\
\hline Total & 1500 & 718 & $(47.8)$ & 108 & $(7.2)$ & 391 & (26.1) & 283 & (18.9) & \\
\hline
\end{tabular}

*By Fisher's exact test

Table 2: Incidence of tear by episiotomy

\begin{tabular}{lccccccc}
\hline & \multicolumn{2}{c}{ No tear } & \multicolumn{2}{c}{ Tear } & \multicolumn{2}{c}{ Total } \\
\hline \multicolumn{1}{c}{ Episiotomy } & No. & $\%$ & No. & $\%$ & No. & $\%$ & P-value \\
No & 283 & 72.4 & 108 & 27.6 & 391 & 100 & 0.006 \\
Yes & 718 & 64.7 & 391 & 35.3 & 1109 & 100 & 100 \\
Total & 1001 & 66.7 & 499 & 33.3 & 1500 & 100 \\
\hline \hline
\end{tabular}


Table 3: SPSS output for logistic regression analysis between tear as a dependent variable with several covariates.

\begin{tabular}{lccccc}
\hline Covariates & B & p & OR & \multicolumn{2}{c}{$95 \%$ C.I. for OR } \\
\cline { 5 - 6 } & & & & Lower & Upper \\
\hline Age (years) & & 0.187 & & & \\
$<\mathbf{2 0}$ & 0.553 & 0.140 & 1.739 & 0.834 & 3.626 \\
$\mathbf{2 0 - 2 9}$ & 0.614 & 0.074 & 1.849 & 0.941 & 3.631 \\
$\mathbf{3 0 - 3 9}$ & 0.398 & 0.255 & 1.488 & 0.750 & 2.953 \\
$\mathbf{4 0 - 4 9}$ (Reference) & & & & & \\
Parity & & 0.049 & & & \\
Primi & 0.174 & 0.455 & 1.190 & 0.754 & 1.880 \\
Multi & 0.401 & 0.053 & 1.494 & 0.994 & 2.245 \\
Grand-multi (reference) & & & & & \\
Baby weight & & 0.033 & & & \\
Low birth weight (reference) & & & & & \\
Normal birth weight & 0.189 & 0.699 & 1.208 & 0.463 & 3.154 \\
Big baby & 0.509 & 0.306 & 1.663 & 0.628 & 4.405 \\
Episiotomy & 0.315 & 0.023 & 1.370 & 1.045 & 1.798 \\
Constant & & & & & \\
\hline
\end{tabular}

the rate of episiotomy was significantly higher (73.9\%) in this study. A study in Turkey (Karacam et al., 2013), of 396 prim parous women found that among the women $56.35 \%$ experienced an episiotomy, $40.2 \%$ experienced vaginal tearing, $11.6 \%$ experienced both and $3.5 \%$ had an intact perineum. These results are not in agreement with the results of this present study [9]. The reported rates of episiotomy, tear and intact perineum in a study done in Iran (Rasouli et al., 2016) were $41.5 \%, 34.7 \%$ and $23.8 \%$ respectively, in which the rate of tear is higher than the results of the present study [10]. The overall rate of episiotomies in a study done in Saudi Arabia was 51.2\%, which is lower compared to the overall rate of episiotomies in this study [11].

The rates of episiotomies and tears in this study are lower when compared to the results obtained from studies done in Italy, and the United States, [12,13] but are higher when compared to results obtained from studies done in the United Kingdom and Nigeria [5,14-17]. Findings from this current study indicate a significant association between age $(p=0.187)$, parity $(p=0.049)$, and birth weight $(p=0.033)$ with perineum status, which agree with the results of other studies done in Turkey, the United Kingdom, the United States and Singapore $[9,15,18,19]$. One study (Howden et al., 20014) found that high educational status, marriage, multiparty, and a history of Cesarean delivery among women 30 years of age and older are independent are independent risk factors for an episiotomy [13].

Another study (Enyindah et al., 2007) found the rate of episiotomy decreased with high parity while the rate of perineal tears slightly increased with parity. 
Nulliparity, vaginal breech deliveries, and instrumental deliveries were identified as risk factors for an episiotomy [16].

In the present study, the incidence of a tear was significantly higher among those who had an episiotomy, compared with those without one. Also, the results show that having an episiotomy will increase the risk of a tear by more than $30 \%$. It is noteworthy that all cases had a mediolateral episiotomy. The increasing risk of a tear in case of episiotomy may be due to the small size of the episiotomy, timing of the episiotomy or the incorrect technique of delivery of the baby by the midwives.

A routine practice among midwives of the Maternity Teaching Hospital is 'hand on'. Midwives in this hospital start lubrication and dilatation of the vaginal opening once the 1st stage of labor has been completed. Ritgen Maneuver applies for all vaginal deliveries at the time of head crowning, as well. Midwives are allowed to do the episiotomy but not to suture it, which is the responsibility of the obstetricians according to the hospital policy.

We observed that midwives perform as small an episiotomy as possible to decrease the surgical trauma to the perineum. These results are supported by results of the review of six randomized trials which showed no differences in vaginal or perineal trauma between patients with and without an episiotomy [20].

Restrictive use of episiotomy policies helps women experience less severe perineal trauma, although overall, women experienced more anterior perineal damage with restrictive episiotomy [17,21].

The limitations of the present study were the variations in recording types and severity of tears, indication of an episiotomy, mother position during the second stage of labor, midwifery technique in perineal support and baby head circumference. In addition, the relationship between oxytocin therapy with the mother's perineal status was not studied.

\section{COUNCLUSIONS}

Maternal age, parity, and birth weight are associated risk factors for perineal trauma resulting in vaginal tearing or an episiotomy. It was found that there is a correlation between having an episiotomy and increased risk factor for vaginal tears. The prevalence of episiotomies in this study is significantly higher than the WHO recommendation. The results from this study suggests that further research is necessary to inform, develop, and implement policies regarding restrictive use of episiotomy.

\section{CONFLICT OF INTEREST}

There is no conflict of interest.

\section{REFERENCES}

[1] Kettle C, Tohill S. Perineal care. BMJ Clinical Evidence 2008; 09:1401

[2] Graham ID, Carroli G, Davies C, Medves JM. Episiotomy rates around the world: an update. Birth 2005; 32(3):219-23. doi: 10.1111/ j.0730-7659.2005.00373.x

[3] Alnakash AH, Jafar S, Abdul-Raheem Y. Whether selective or routine episiotomy is more useful to protect anal sphincter in primiparous women. Iraqi Journal of Medical Science 2012; 11(1):26-32

[4] Carroli G, Mignini L. Episiotomy for vaginal birth (review). Cochrane Database of Systematic Reviews 2009, Issue 1 . doi: 10.1002/14651858.CD000081.pub2.

[5] Piro SS, Ahmed HM. Midwives' perspectives regarding episiotomy practice in Kurdistan region/Iraq. Zanco Journal of Medical Science 2016; 20 (1): 1233-43. doi: http:// dx.doi.org/10.15218/zjms.2016.001.

[6] Ahmed HM. Midwives' Clinical Reasons for Performing Episiotomies in the Kurdistan Region: Are they evidence-based? Sultan Qaboos University Medical Journal 2014 Aug; 14 (3): e369-74. 
[7] World Health Organization Division of Family Health Maternal Health and Safe Motherhood. Care in normal birth: a practical guide. Report of a technical working group. Geneva: World Health Organization; 1996.

[8] Holmes D, Baker PN ed. Midwifery by Ten Teachers. London, UK: CRC Press; 2006. pp. 239-41

[9] Karacam Z, Ekmen H, Calisir H, Seker S. Prevalence of episiotomy in primiparas, related conditions, and effects of episiotomy on suture materials used, perineal pain, wound healing 3 weeks postpartum, in Turkey: A prospective follow-up study. Iran Journal of Nursing and Midwifery Research 2013; 18 (3): 237-45.

[10] Rasouli M, Keramat A, Khosravi A, Mohabatpour Z. Prevalence and Factors Associated With Episiotomy in Shahroud City, Northeast of Iran. International Journal of Women's Health and Reproduction Sciences 2016; 4 (3): 125-9. doi: 10.15296/ijwhr.2016.29

[11] Saadia Z. Rates and Indicators for Episiotomy in Modern Obstetrics - a study from Saudi Arabia. Mater Sociomed 2014 Jun; 26(3): 188 -190. doi: 10.5455/msm.2014.26.188-190

[12] Bertozzi S, Londero A, Fruscalzo A, Driul I, Delneri C, Calcagno A, etal. Impact of episiotomy on pelvic floor disorders and their influence on women's wellness after the sixth month postpartum: a retrospective study. BMC Women's Health 2011; 11(12). doi:10.1186/1472-6874-11-12

[13] Howden NL, Weber AM, Meyn LA. Episiotomy use among residents and faculty compared with private practitioners. Obstetrics and Gynecology 2004; 103(1): 114-8.

[14] Inyang-Etoh EC, Umoiyoho AJ. The practice of episiotomy in a university teaching hospital in Nigeria: How satisfactory? International Journal of Medicine and Biomedicl Research 2012; 1(1):68-72

[15] Robinson J, Norwitz E, Cohen A, Lieberman E. Predictors of episiotomy use at first spontaneous vaginal delivery. Obstetrics and Gynecology 2000; 96(2): 214-18

[16] Enyindah CE, Fiebai PO, SE Anya, Okpani AO. Episiotomy and perineal trauma prevalence and obstetric risk factors in Port Harcourt, Nigeria. Nigerian Journal of Medicine 2007; 16(3):242-5

[17] Chigbu B, Onwere S, Aluka C, Kamanu C, Adibe E. Factors influencing the use of episiotomy during vaginal delivery in South Eastern Nigeria. East African Medical Journal 2008; 85(5): 240-3
[18] Gossett DR, Dunsmoor Su. Episiotomy practice in a community hospital setting. Journal of Reproductive Medicine 2008; 53(10):8038.

[19] Wu LC, Malhotra R, Allen JC, Lie D, Tan TC, Ostbye T. Risk factors and midwife-reported reasons for episiotomy in women undergoing normal vaginal delivery. Arch Gynecology and Obstetrics 2013; 288:1249-56. doi: 10.1007/s00404-013-2897-6. Epub 2013 May 26.

[20] Repke J. When is episiotomy warranted? What the evidence shows. OBG Management 2003;15(10):46-54

[21] Klein MC, Gauthier RJ, Robbins JM, Kaczorowski J, Jorgensen SH, Franco ED, et al. Episiotomy should be used only for specified fetal-maternal indications. American Journal of Obstetrics and Gynecology 1994; 171:591-8 